\title{
Proliferation of Bovine Albumin Serum on Nano-Scale Titanium Nitride Coated Stainless Steel Substrates for Biomedical Applications
}

\author{
Sumaira Nosheen", Shahzad Alam, Muhammad Irfan, Bilal Waseem, Muhammad Shahid, \\ Badaruddin Soomro, Quratulain Syed \\ Pakistan Institute of Technology for Minerals \& Advanced Engineering Materials (PITMAEM), PCSIR Labs. Complex, Lahore, Pakistan
}

Email address:

sumera_pcsir@yahoo.com (S. Nosheen), chairman@pcsir.gov.pk (S. Alam), pitmaem.lhr@gmail.com (M. Irfan), badar.soomro@hotmail.com (B. Soomro),quratulainsyed@yahoo.com (Q. Syed)

*Corresponding author

To cite this article:

Sumaira Nosheen, Shahzad Alam, Muhammad Irfan, Bilal Waseem, Muhammad Shahid, Badaruddin Soomro, Quratulain Syed. Proliferation of Bovine Albumin Serum on Nano-Scale Titanium Nitride Coated Stainless Steel Substrates for Biomedical Applications. International Journal of Biomedical Materials Research. Vol. 5, No. 5, 2017, pp. 64-67. doi: 10.11648/j.ijbmr.20170505.12

Received: May 29, 2017; Accepted: June 13, 2017; Published: November 24, 2017

\begin{abstract}
Biocompatible and corrosion resistant coatings are frequently used to protect and enhance the life time of bioimplants. TiN (titanium nitride) is being used as coating material on different surgical and orthopedic implants due to its excellent biocompatibility. TiN coatings are attractive because of low coefficient friction, high hardness, chemical inertness and smooth surface finish, which they will provide to biochemical devices. These coatings were prepared by PVD (physical Vapor deposition) technique on SS 304L plates to investigate the protein adhesion on coated stainless steel samples. The protein adhesion and growth of Bovine Albumin Serum (blood protein) on coated samples was checked. Surface of coated material and protein growth on coated material was investigated using AFM (atomic force microscope), SEM and FTIR.
\end{abstract}

Keywords: Biocompatibility, Bovine Albumin Serum, Coated Implants

\section{Introduction}

The human body contains a wonderful system, which has incorporated load-bearing mechanism having self-replicating system which is adaptable to changes in environment. It is always a tough task for scientists when they attempt to design procedures, components and systems for the replacement of tissue damaged by disease or trauma. It is a major challenge to select a correct material for prostheses and other devices that are used in implant surgery [1]. The properties of biomaterial should be compatible enough considering that human body is so sensitive and should not disturb the various functions of human body. The prime requirement for the implants is their ability to resist the surrounding cells and body fluids both chemically and biologically. For this purpose a new method is expected to fabricate human body implants which are more bio compatible and durable. In this way, a material should be selected as a substrate that has improved mechanical properties showing better mechanical strength. Further this substrate is coated with biocompatible layers that have excellent corrosion and erosion resistance [2]. Most common metals like titanium, some grades of stainless steel like 316 or 304 , titanium oxide, titanium nitride, cobalt-chromium alloy, and nickel alloys have been used for different biomedical applications. The main failure of using these alloys is cytotoxicity, corrosion, and less wear resistance when subjected to a body fluid for a longer time. A big drawback of using stainless steel as implant in many biomedical applications is that it can release certain ions like $\mathrm{Cr}, \mathrm{Ni}, \mathrm{Mn}$, and Mo in coronary vessels $[3,4,5]$. Stainless steel implants were used earlier as bulk material for implants because of their high strength and corrosion resistance, but there was no enough awareness among the researchers about hazardous effects of these alloys. An important approach regarding biocompatible devices was carried out by depositing layers on the surfaces which should be inert and corrosion resistant as well as adhesive to biological fluids. This is the key that the coated materials became important 
and gained fame in medical field [6].

Earlier, diamond-like carbon (DLC) coatings were used as major tool to coat different steel types to be used in medical areas. Dowling et al., picked these Diamond-like carbon (DLC) coatings and deposited them onto austenitic stainless steel hip implants using a saddle field source deposition system. The coated implants presented a significantly lower level of wear after 6 million cycles on the simulator as compared to uncoated surfaces [7]. Feng studied the relationship between the characterization and adsorption of bovine albumin serum on Titanium Metal and observed the oxide films formed at the surface. The adsorption of albumin on the titanium surfaces was positively related with the amounts of their surface hydroxyl groups, including basic hydroxyl groups and acidic hydroxyl groups, and the values of the polar component of the total surface energy [8].

The reason for selecting Titanium nitrides is that it possesses good tribological properties and biocompatibility [9]. TiN layers possess excellent intrinsic biocompatibility [10-12]. Dion et al. [13] also presented the use of TiN in left ventricular assisted devices. Mitamura et al. [14] showed that the blood compatibility of low-temperature isotropic pyrolytic carbon is comparable with TiN films. Researchers have characterized TiN as having a very high chemical inertness, low friction coefficient, and good biocompatibility [15]. In the medical field, TiN has been used to reduce the abrasion resistance and increase the hardness and corrosion resistance of surfaces and diminish the interaction of biological liquids with the metal bases [16].

However the Surface properties like surface chemistry, surface energy and surface topography can be critical for implants biocompatibility, along with bulk properties. Protein adsorption, which is a virtually direct process during an implantation procedure, is a dynamic and a very complex phenomenon. Implant surface properties include interfacial free energy, hydrophobicity and surface charge density. In current study, Stainless steel substrates were coated with adherent TiN coatings developed by Physical Vapor Deposition (PVD) technique. In vitro bioactivity was assessed to check the adsorption behavior of bovine albumin serum with TiN coated stainless steel implants and biocompatibility evaluation was also carried out.

\section{Experimental}

Smooth and uniform TiN coating was deposited on stainless steel samples $(\varnothing 1 \times 1$ inch), through PVD (physical vapor deposition) technique. The chemical composition of the substrate was confirmed by Optical Emission Spectrometer (Metal Lab 75-80J). The confirmation of substrate was followed by the preparation of the surface. The samples were fine grinded and polished till $1 \mu \mathrm{m}$ using the diamond paste. The polished surfaces were then checked for their roughness analysis. SURFCORDER Surface profilometer was used for roughness analysis. After obtaining the required roughness, samples were cleaned in different media in order to remove any dust or contaminants from the surface before coating process. Initially the samples were placed in ultrasonic cleaning bath containing carbon tetra chloride solution. Temperature of bath was maintained at $30^{\circ} \mathrm{C}$ and cleaning was carried out for 30 minutes. $\mathrm{CCl} 4$ removes all the greasy material stuck to the surface. After this, the samples were washed with Distilled water. Same process was repeated using acetone in the bath to remove any dust and contaminants from the surface. Final cleaning was carried out by using cleanogel solution in the bath and eventually washing with distilled water. The cleaned surface was then taken to the coating chamber for the coating process. The coating process takes place inside the vacuum chamber. This chamber is mechanically stable and vacuum tight. It must resist high stress caused by temperature, air pressure and water circuit. The chamber consists of cathode (Ti) and targets (substrate to be coated), the heater and the substrate holder unit, which is called "carrousel". The chamber walls as well as door are cooled by the running water.

The PVD process takes place in vacuum. The evaporation sources which are incorporated into the door, provide highly ionized metallic vapors. This metallic vapor arises from an arc discharge between cathode (Ti) and the recipient. In reaction with nitrogen, the Titanium vapors combine to metallic nitrites. Finally these nitrites are deposited on the substrates. The result of this coating process is hard, smooth surfaces with a very high adhesion. The coating process was carried out in nitrogen atmosphere. The working pressure was maintained at 1.5 Pa. Prior to this, the samples (HSS drills \& test coupons) were cleaned \& mounted on carrousel substrate holders. This carrousel rotates uniformly around the central axis at a speed of $12 \mathrm{rpm}$.

For in vitro testing, Bovine Albumin Serum was provided by Sigma Aldrich, $100 \mathrm{ml}$ protein solution (Bovine Albumin) was prepared $[17,18]$ by taking $5 \mathrm{mg}$ of bovine albumin in $100 \mathrm{ml}$ of double distilled water in a sterile beaker and coated samples were soaked in it for 24 hours at 4 degree centigrade in controlled conditions according to in vitro methods"/EN 30993-5. Samples were washed with a $90 \%$ methanol solution, $8 \%$ de-ionized water and $2 \%$ glacial acetic acid. Then amount of protein adsorbed on the surface was calculated for 24 hours, 12 hours and 1 hour respectively. Samples were evaluated for cell adhesion using atomic force microscope (AFM) and Fourier transform infrared spectroscopy (FTIR). Scanning Probe Microscope (SPM) CP-II was used for the AFM analysis to check the adhesion of protein with the coated surface. The analysis was carried out in the contact mode and area of 10 by $10 \mu \mathrm{m} 2$ was scanned during AFM analysis in the topography mode. The scanning rate was maintained at $1 \mathrm{~Hz}$ and the set point value was adjusted at $13 \mathrm{nN}$. All scans were taken in $\mathrm{X}$ direction and the gain parameter was adjusted at 0.35 .

\section{Results and Discussion}

Table 1. shows the chemical composition of Stainless steel substrates on Emission Spectrometer, which appears to be AISI 304L. The surface roughness of Titanium Nitride coated 
surface was measured using Scanning Probe Microscope (SPM CP-II Veeco). $30 * 30 \mu \mathrm{m}^{2}$ area of the coated surface was scanned using the contact mode of Atomic Force Microscope (AFM). The scanning was carried out in the forward direction and the scan rate was adjusted at $15 \mu \mathrm{m} / \mathrm{s}$. The average surface roughness was $33.25 \mathrm{~nm}$. Two dimensional and three dimensional views of the coated surface are also shown in the figure 1. Adsorbance of Bovine Albumin Serum on Coated implants was $165 \mu \mathrm{g} / \mathrm{cm}^{2}$ showing more adsorbance as compared to DLC coated implants reported in literature $[9,10]$. The bright portions in figure 1a depict the presence of protein on the coated surface, which is also confirmed by figure $1 \mathrm{~b}$ (3D image). A scanning electron microscope (SEM) image of Titanium Nitride coated samples immersed in protein is shown in figure 2 (a). The image was taken at $1000 \mathrm{X}$ magnification. The image clearly depicts the adsorption of protein particles on coated surface. The peaks of carbon, oxygen and nitrogen confirm the presence of amino acids on the coated surface, which are the basic building blocks of proteins. The figure 2 (b) clearly describes the homogenous accumulation of protein on the coated surface, which is confirmed by both visual \& chemical analysis. The Samples were also assessed by FTIR after dipping in protein. The peaks show the presence of carboncarbon, carbon-nitrogen and carbon-oxygen stretching and bending bands. The spectrum obtained clearly confirmed the presence of amino acid groups on the surface of coated sample as shown in figure 3.

Table 1. Chemical composition of SS 304L sample.

\begin{tabular}{|c|c|c|c|c|c|c|c|}
\hline elements & Carbon & Manganese & Phosphorus & Sulphur & Silicon & Nicked & Chromium \\
\hline \%age & 0.027 & 2.071 & 0.027 & 0.014 & 0.567 & 8.084 & 18.792 \\
\hline
\end{tabular}
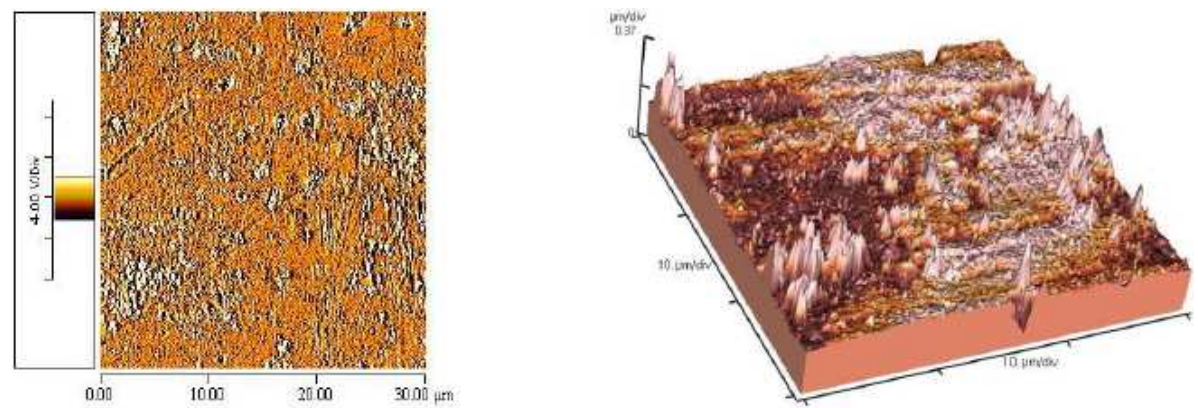

Figure 1. Surface of TiN coated stainless steel samples after 24 hours of immersion as observed by AFM (a) surface image (b) $3 D$ Image.
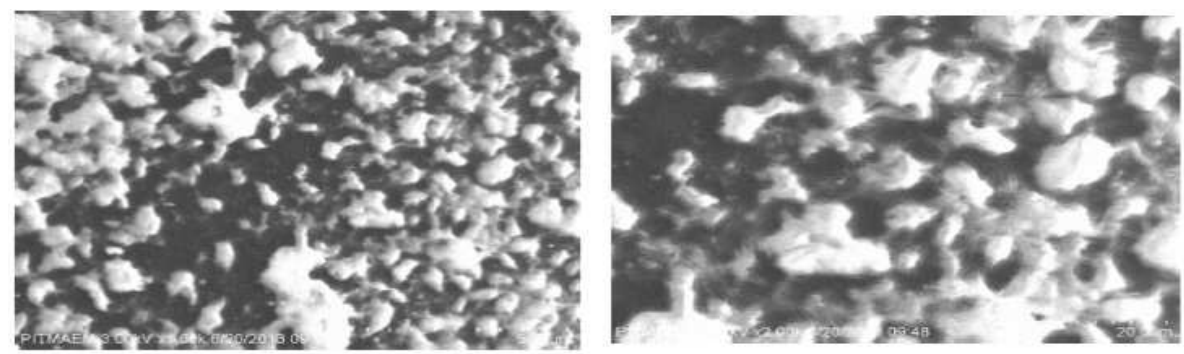

Figure 2a. Showing SEM Images of protein dipped sample.
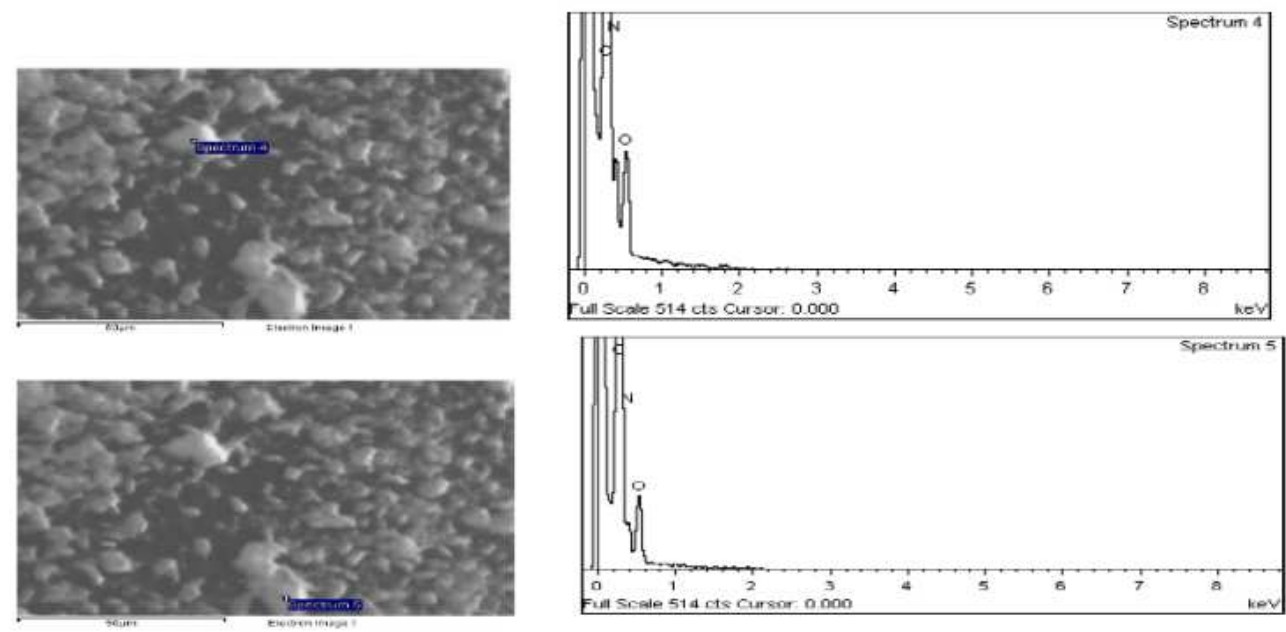

Figure 2b. Energy Dispersed X-Ray Spectrum showing peaks of Carbon. Nitrogen \& Oxygen. 


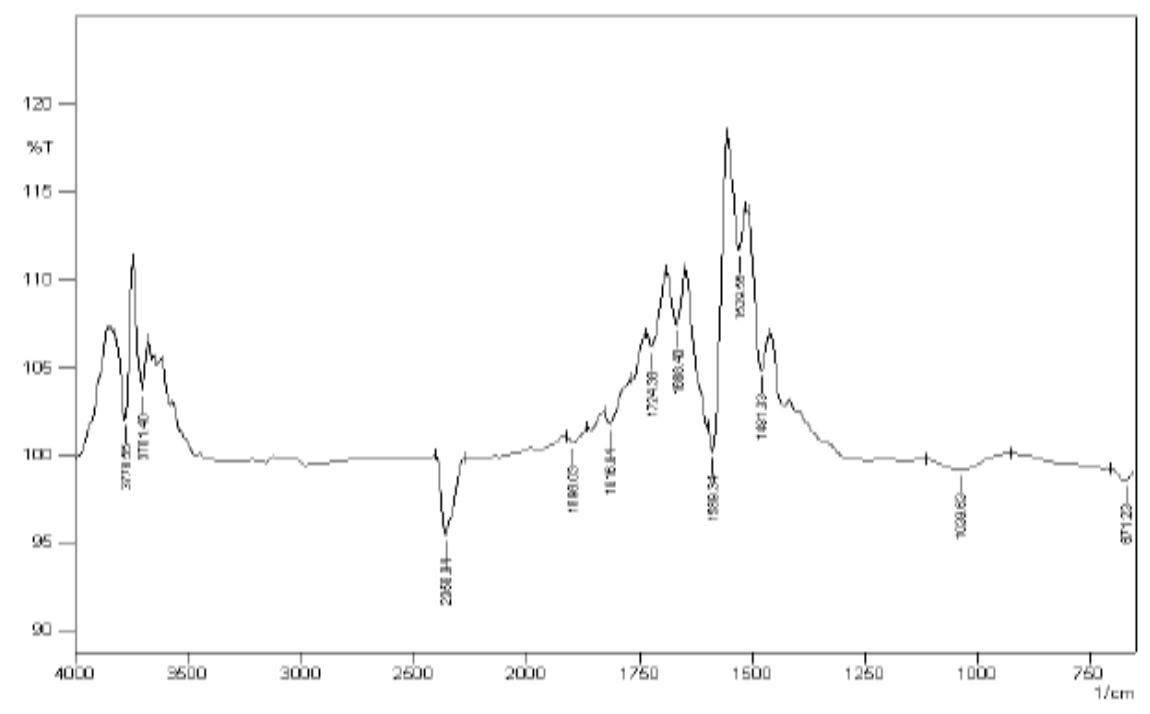

Figure 3. FTIR results for protein dipped sample.

\section{Conclusion}

Day by day there is immense increase in demand of implants and their applications in surgeries as the world's population is increasing drastically. Because of this new challenges are increasing so fast that the need for increase in coating technologies becoming very fast. A suitable cellular response to implant surfaces is considered to be indispensable for tissue rejuvenation, integration and proper growth. It can be clearly observed that surgical materials are instantly coated with proteins, which are present in blood and it happens through this adsorbed layer that cells immediately respond to the foreign surfaces. Consequently, the adsorbed proteins will respond itself rather than the surface beneath the protein layer. These actions bring about the successive responses which are mandatory for tissue repair, with the nature of cell surface responses that are causative to survival normal growth of tissue. The excellent set of intrinsic quality of stainless steel (bio inertness) can be auxiliary enhanced by adherent, auto lubricious, biocompatible and more effective TiN coatings concerning hip replacement and other medical applications.

\section{References}

[1] Journal of Materials world, Vol.12, pp. 31, February 2004.

[2] http://www.sciencedirect.com/science/article/pii/09215107949 01937.

[3] Huang N, Yang P, Leng YX, Chen JY, Sun H, Wang J, Wang GJ, Ding PD, Xi TF, Leng Y. Hemocompatibility of titanium oxide films. Biomaterials 2003; 24: 2177-2187.

[4] Shah AK, Sinha RK, Hickok NJ, Tuan RS. High-resolution morphometric analysis of human osteoblastic cell adhesion on clinically relevant orthopedic alloys. Bone 1999; 24:499-506.

[5] Gutensohn K, Beythien C, Bau J, Fenner T, Grewe P, Koester R, Padmanaban K, Kuehnl P. In vitro analyses of diamondlike carbon coated stents: Reduction of metal ion release, platelet activation and thrombogenicity. Thromb Res 2000; 99: 577-585.
[6] Cui FZ, Luo ZS. Biomaterials modification by ion beam processing. Surf Coat Technol 1999; 112:278-285.

[7] Dowling, D. P., Kola, P. V., Donnelly, K., Kelly, T. C., Brumitt, K., Lloyd, L., ... \& Weill, N. (1997). Evaluation of diamond-like carbon-coated orthopedic implants. Diamond and Related Materials, 6 (2), 390-393.

[8] Feng, B., Weng, J., Yang, B. C., Chen, J. Y., Zhao, J. Z., He, L. \& Zhang, X. D. (2002). Surface characterization of titanium and adsorption of bovine serum albumin. Materials Characterization, 49 (2), 129-137.

[9] Surface \& Coatings Technology, pp-3701 vol. 203 (2009).

[10] A. Wisbey, P. J. Gregson and M. Tuke, Journal of Biomaterials, vol. 8, pp-477 (1987).

[11] W. Franks, I. Schenker, P. Schmutz. Hierlemann, IEEE Transactions on Biomedical Engineering, VOL. 52, NO. 7, pp1295 (2005).

[12] C. T. Kao, S. J. Ding, Y. C. Chen and T. H. Huang, Journal of Biomedical Material Research., vol. 63, 786 (2002).

[13] I. Dion, X. Roques, N. More and L. Labrousse, Journal of Biomaterials, vol. 14, pp-712 (1993).

[14] Y. Mitamura, K. Hosooka, T. Matsumoto, K. Sakai, T. Tanabe, T. Yuta and T. Mikami, Journal of Biomaterial Applications, vol. 4, pp-33 (1989).

[15] Galante, J. O., Lemons, J., Spector, M., Wilson, P. D., \& Wright, T. M. (1991). The biologic effects of implant materials. Journal of orthopaedic research, 9 (5), 760-775.

[16] Harman, M. K., Banks, S. A., \& Hodge, W. A. (1997). Wear analysis of a retrieved hip implant with titanium nitride coating. The Journal of arthroplasty, 12 (8), 938-945.

[17] Roy RK, Choi HW, Yi JW, Moon MW, Lee KR, Han DK, Shin JH, Kamijo A, Hasebe T. Acta Biomaterialia, vol. 5, pp249 (2009).

[18] Jones MI, McColl IR, Grant DM, Parker KG, Parker TL. Journal of Biomedical Material Research, vol. 52, pp-413, 2009. 